\title{
V9 Thermostability study of meningococcal conjugate bulks produced for phase III clinical trials
}

Milton Neto da Silva ${ }^{1}$, laralice Medeiros de Souza ${ }^{1}$, Renata Chagas Bastos $^{1}$, Marilza Barbosa Corrêa ${ }^{1}$, Camila da Silva Faria ${ }^{1}$, Ana Paula dos Santos ${ }^{1}$, Ivna Alana Freitas Brasileiro da Silveira ${ }^{1}$

${ }^{1}$ Bio-Manguinhos, Fiocruz, RJ

Introduction: Neisseria meningitidis is one of the most important pathogens as causes of meningitis and other clinical manifestations worldwide. Bio-Manguinhos has developed all steps to produce, purify and control an effective Brazilian meningococcal $\mathrm{C}$ conjugate vaccine by modified reductive amination where oxidized-polysaccharide was coupled to hydrazide-activated monomeric tetanus toxoid used as carrier protein.

Objective: This work is related to monitoring of physical-chemical and immunological modifications after conjugate bulks storage at different temperatures in order to establish technical requirements of quality.

Methodology: Three conjugate bulks were produced in industrial scale for Phase III clinical trials in 2012. Samples from each batch in triplicate were stocked at $2-8^{\circ} \mathrm{C}$ (control group), $25^{\circ} \mathrm{C}, 37^{\circ} \mathrm{C}$ and $55^{\circ} \mathrm{C}$ during 5 weeks. Quality control analysis followed WHO recommendations as $\mathrm{pH}$, sugar free content, SEC-HPLC profile, 1H NMR spectra, sialic acid content and mice immunogenicity.

Results: Sialic acid amount and $\mathrm{pH}$ values did not show expressive variation after 5 weeks of storage at all temperatures. However in $1 \mathrm{H}$ NMR spectra were observed structural modifications in carrier protein with temperature increase $\left(37\right.$ and $\left.55^{\circ} \mathrm{C}\right)$. Signals related to aromatic and aliphatic amino acids degradation were observed at 6.5 to $7.5 \mathrm{ppm}$ and 2.90 to $3.32 \mathrm{ppm}$ range, respectively. Considering SEC-HPLC results all samples were approved according to Kav range (0.2 to 0.35 ). On the other side, sample profiles stocked at 37 and $55^{\circ} \mathrm{C}$ showed a peak arising with elution in $10.5 \mathrm{~mL}$ as detected by $254 \mathrm{~nm}$. Additionally it was observed a peak base broadening in samples stocked at $55^{\circ} \mathrm{C}$, suggesting product degradation. The conjugate bulks samples were also analyzed by ultraviolet in a scanned mode where were observed two bands in 220 and $280 \mathrm{~nm}$. For samples stocked at $55^{\circ} \mathrm{C}$ there was a small hypsochromic shift which means modification in tertiary structure of protein portion. In Capillary Electrophoresis assays it was observed a progressive increase of a peak correspondent to sugar free and also the appearance of a peak with protein similarity. Samples stocked at 37 and $55^{\circ} \mathrm{C}$ showed unconjugated sugar values above the specified limit (20\%). 
Conclusion: These results suggest some modifications in physicalchemical parameters related to structural changes of glycoconjugate and conformational alterations in carrier protein requiring the strict control of storage temperature. Immunogenicity of these samples is being evaluated in mice in order to check temperature interference in immune response induced by Brazilian meningococcal $\mathrm{C}$ conjugate vaccine.

Keywords: Meningococcal Vaccine, Thermostability 